\title{
Development Studies: The Struggle for Recognition
}

\section{Colin Fuller}

There were some, and may have been many, who, like myself, groaned when they received the paper with the titles for the Discussion Groups at the Third National Development Conference held in Manchester in September 1976 and saw that the first topic listed was 'The need for a British Development Studies Association.' First reactions were sceptical, with remarks exchanged about 'empire-building', 'talking-shops' and the failures of similar groups in the past. However, as the conference progressed and I reflected on the role and needs of teachers of subjects concerned with development and, more importantly, on the needs of the public officials and other students from the Third World who participate in study programmes in the Department of Administrative Studies in Manchester University and similar institutions, the potential contribution of a Development Studies Association became more evident.

We are caught up in a hierarchy of needs, all of which require identification as possible barriers to the growth of development studies, and ultimately to development itself. One of the more obvious needs, which may also be a barrier, is specialisation. Professionals in most organisations are concerned with specialised work and this is particularly true of university departments. These specialists are vital to any organisation and it is largely from their striving for excellence that many discoveries are made and new theories developed. In business specialisation leads to invention and innovation; in the university it leads to the expansion of knowledge, the proof of one theory or the disproving of another. The dedicated specialist may, however, also be a danger, especially in a field where problems and their diagnosis and solution are rarely to be found within the confines of a single discipline. To the extent that the specialism or discipline becomes to be regarded as an end in itself, its contribution to an interdisciplinary subject such as development studies will become less useful.

Closely related to the problem of over-specialisation is the effect of organisational structure. Most universities are organised in such a way that the boundaries of departments and disciplines are synonymous. With few exceptions, staff soon learn that it is in their own interest to teach, do research and publish within the departmental discipline and dangerous to stray beyond its con- fines. In today's conditions of financial stringency it is to be expected that those responsible for the allocation of resources in university departments will be even more careful to avoid what they may regard as dysfunctional and wasteful use of departmental resources. Departmental needs may thus sometimes prevent attempts by individuals or groups to adopt a more catholic approach to development studies. The proposed introduction of a new Diploma or M.A. in development studies is likely to raise questions such as 'What's in it for us' and 'what harm could it do us', sometimes outweighing questions about relevance for the students. This may not only be inevitable but, some may argue, the proper approach for those whose task is to safeguard the interests of their organisations. Is one being too naive in thinking that it should be possible for factors other than those of self-interest to influence decisions about such studies.

This note has tended to stress negative factors influencing development studies, but one might suggest that they represent greater obstacles to development than that of identifying the problems of development themselves. Even though this may be too great a claim there would appear to be ample evidence for supporting needs of a positive nature:-

1. The need for more dialogue and, hopefully, better understanding between all those concerned with development studies irrespective of their department or discipline of origin.

2. The need for acceptance and acknowledgement of the importance of a wide variety of disciplines and specialisms on which development studies draw.

3. The need to accept that occasionally some 'watering-down' of standards may be necessary and in some circumstances, even desirable, in order to communicate certain aspects of development studies to particular clientèles. In this connection it should not be overlooked, however, that frequently the inter-marriage of disciplines enhances a study and makes possible a breadth and excellence of work that would not otherwise be possible.

As Colin Leys pointed out in the preface to his book Underdevelopment in Kenya "The original formulation of the problem in terms of 'the private sector', and even more fundamentally, 
in terms of 'the economy' as something distinct from 'the political system', soon appeared not merely artificial but as a positive obstacle to grasping the reality involved. This was not merely a question of being willing to transgress 'disciplinary' boundaries, but of trying to establish a standpoint from which all the concepts in terms of which the Kenyan experience had hitherto mainly been described could be critically reconsidered."

4. There may also be a need for those engaged in development studies not to engage themselves in costly arguments about identity and legitimacy. In an article in the September 1976 edition of the Journal of Political Studies entitled 'Irresistible Forces: the Pressures for a Science of Politics', Jeffrey Stanyer concludes as follows: "If 'what we are doing' is justified, then 'what we are' loses its interest; the former is a sufficient answer to those who would deny the study of politics a place in the academic heaven". In a different context, perhaps this statement might be made with equal emphasis about development studies.

5. To what extent is there a need for greater commitment of a moral and social nature by individuals and groups who are involved in development studies for the Third World whether as researcher, consultant or teacher. During the discussion which followed the final session at the Third National Development Conference, in which Sartaj Aziz presented a theoretical framework for rural development, one of the speakers made a passionate statement that as individuals we needed to show where we stood. It was not completely clear whether he meant $v i s-\grave{a}$-vis the countries of the Third World or to the left or right politically (or perhaps both). Is this important and, if it is, to what extent? The main document published by the International Labour Organisation for the World Employment Conference in June of last year shows a marked change in thinking-from concern about employment to concern about poverty and basic needs. The ILO has indicated where it stands and, whilst it would not be feasible for development studies to be concerned solely and directly with the eradication of poverty, commitment to this as a penultimate objective for us all might not be a bad thing.

This note has attempted to outline some of the obstacles to more relevant development studies. It is written from the standpoint of one who spends more time reading about development and teaching on practically orientated study programmes for public officials from the Third World, than on research overseas. The number of those in a similar position or, with the present economic climate, in a situation where they cannot obtain funds for research overseas at all, is likely to increase. Thus, greater numbers rather than fewer will be turning to material researched and published by others. Most of this, if it follows the traditional pattern, will stem from and reflect the single discipline approach for the reasons outlined in this essay. If this happens it will present teachers and students of development studies with material which rarely illustrates the true nature of development problems which, more often than not, have many facets representing several disciplines. Whilst no one person can be omniscient or produce work of a consistently high standard across several disciplines, is there not a strong case for encouraging individuals to undertake studies which will include areas which traditionally would be regarded as outside the boundaries of their discipline or for individuals from different disciplines to work together on common development studies with an interdisciplinary approach. Both these approaches have been tried in the past with mixed success and they present real difficulties, but even if a truly interdisciplinary approach is not possible in some cases, perhaps an inter-related one will go part of the way to meeting students" needs.

The main role of the proposed British and Irish Development Studies Association as expressed in a paper dated 31st October 1976 from the Steering Committee will be "to promote interdisciplinary development studies through meetings, conferences, and the circulation of information; and the encouragement of the discussion of the underlying theoretical and methodological issues. In addition, the Association may also be involved in the dissemination of research results and with the discussion of course curricula and training facilities." The writer, who has no connection with this Steering Committee, hopes that the Association will be able to maintain its interdisciplinary position, that its members will be encouraged by heads of departments and institutes to cross the conventional boundaries between disciplines so that we may all benefit from their work which will, hopefully, reflect development studies in the true context of their environments which are multi-disciplinary. 